\title{
A REVISION OF THE AMERICAN LICE OF THE GENUS PEDICULUS, TOGETHER WITH A CONSIDERATION OF THE SIGNIFICANCE OF THEIR GEOGRAPHICAL AND HOST DISTRIBUTION
}

\author{
By H. E. Ewing, \\ Bureau of Entomology, United States Department of Agriculture
}

\section{INTRODUCTION}

Because the genus Pediculus includes lice parasitic on man, it has always been one of great interest and economic importance. Head and body lice not only have the disgusting annoyance caused by their parasitic habits, but they are known to be the transmitters of some serious human diseases such as a typhus and trench fever. From a biological standpoint it is in their variation, geographical distribution, and host relationships that the members of the genus offer their greatest interest, and in this respect they have long furnished an absorbing although puzzling problem to scientists. Almost a century ago entomologists were saying, but by no means proving, that different races of mankind each harbored a different race of Pediculus. Since then in each decade at least some one writer has renewed the old assertion and in complete conformity with his predecessors has failed to substantiate it.

When we reflect that it has only been in the last 10 or 15 years that any reliable technique has been employed in the taxonomic study of any of the sucking lice, there is little wonder that the early entomologists with their crude microscopes, or in some cases hand lenses, consistently disagreed with one another in regard to their observations. In the last 10 years methods of clearing, staining, and even dissecting have been developed in connection with the aid of efficient and high-powered microscopes so that now it is possible to ascertain far more accurately small differences which exist among closely related species and varieties. Also time and better transportation facilities have made it possible to enlarge our collections of both hosts and parasites, and thus obtain a better knowledge of their distribution. Because of these new conditions it has appeared to the writer that a revision of the genus Pediculus could be made with profit and some expectation of adding stability to the taxonomy and nomenclature of the group. At first it was hoped that a compre-

No. 2620.-Proceedings U. S. National Museum, Vol. 68, Art. I9 $79652-26-1$ 
hensive treatment of the genus for the whole world could be undertaken, but lack of sufficient material from the Old World made this consideration impossible. After long delay the want of sufficient material even from the New World has made it necessary to reduce decidedly the scope of the present paper.

As already said, the early entomologists held that each of the races of mankind harbored a distinct form of Pediculus. It has remained, however, for Fahrenholz (1913, 1915), alone of the living entomologists, actually to demonstrate, in certain instances, according to the viewpoint of the present writer, that there are distinct forms of Pediculus for certain racial units of mankind. This German scientist, however, has gone to the extreme of recognizing in one instance as many as three distinct types of Pediculus for a single primitive race of man.

It is the intent of the writer not only to review in this paper much of the work of Fahrenholz and others, but to give what he thinks is the proper taxonomic arrangement of the American members of the genus and also to elaborate in more detail some ideas in regard to the significance of host relationship set forth in a preliminary note published in Science (Ewing, 1924).

THE GENUS PEDICULUS LINNAEUS AND THE NAME OF ITS TYPE SPECIES

The genus Pediculus was established by Linnaeus in the tenth edition of his Systema Naturae, page 610. His diagnosis follows:

Pedes VI, ambulatorii.

Oculi II.

Os aculeo exserendo.

Antennae longitudine thoracis.

Abdomen depressum sublobatum.

In this genus Linnaeus placed not only the sucking lice of man but a large number of other lice, chiefly from domestic animals. Also he did not at the time of the publication of the tenth edition of his Systema Naturae differentiate between the head louse and the body or clothes louse, including both under his Pediculus humanus. In his twelfth edition Linnaeus does differentiate between the head louse and the clothes louse, but he speaks of them as varieties 1 and 2 , these designations having no validity according to modern rules of nomenclature. The first one to use varietal names for the two forms of Pediculus was De Geer, who in 1778 called the head louse variety capitis and the clothes louse variety corporis. These are the designations by which both of these forms have been frequently referred to in recent literature, yet, of course, the name humanus Linnaeus must have priority over one or the other of them. It should 
be added that corporis De Geer (1778) has priority over vestimenti Nitzsch (1818), a name which is also frequently applied to the clothes louse.

When in 1778 De Geer gave the varietal name capitis to the head louse and corporis to the body or clothes louse he did not employ the specific name, repeated as a varietal name, to represent either of his varieties-which is required according to modern usagehence there has been some question as to which varietal name of De Geer should be dropped.

It appears to the writer that the name humanus (either varietal or specific) of Linnaeus should be applied to the head louse for two reasons. In the first place it was the variety first described by $\mathrm{De}$ Geer in 1778. In the second place, it is the head louse that has long been considered as the genotype of Pediculus where the two forms have been regarded as distinct species.

The whole matter is somewhat involved and apparently is not sufficiently covered by our entomological codes of nomenclature or by the International Code of Zoological Nomenclature.

CHARACTERS OF TAXONOMIC VALUE IN THE GENUS PEDICULUS

The characters which have been most used in the past for taxonomic purposes have had to do largely with size, degree of chitinization, ratio of lengths of antennal segments, and chaetotaxy. Undoubtedly such characters have much taxonomic value, but the range of individual variation and the possible effects of hybridization should be taken into consideration at all times.

Mjöberg (1910) used the shape of the genital plate of the female and the form of the gonopods in differentiating his $P$. affinis from $P$. consobrinus Piaget. Fahrenholz (1917) used a large number of characters including size, pigmentation, chaetotaxy, shape of gonopods, shape of antennal segments, etc. Nuttall (1920) pointed out and, according to the view of the present writer, demonstrated that size is such a variable character that its use in taxonomic differentiation should be with much reservation and caution; also, he demonstrated that coloration was so variable a character as to be wholly unreliable for taxonomic purposes. He showed that not only was there great variation between individuals in regard to pigmentation but also that the degree of pigmentation was dependent chiefly on environment, and he further showed that in a single individual certain parts would vary in their pigmentation in a more or less indiscriminate manner. Among the characters that Nuttall (1920) found to be of value are: The shape of the head, the length of the antennae, and the shape of the sixth abdominal segment.

In the course of the writer's study it was found that in specimens properly cleared and mounted the pleural plates offered characters 
of fundamental importance for the separation of the different species of the genus. These plates are observed to best advantage from the side, and such a view may be obtained by stripping off the lateral portion of the abdominal wall with a very small and sharp scalpel and mounting this strip separately on a microscope slide; or if specimens are treated with strong caustic and then much of the body contents worked out through a small hole made in the body wall, the walls will collapse when the specimens are mounted, and in doing so will bring the pleural plates into a horizontal position.

In addition to the structures of the pleural plates the writer has found that the chaetotaxy of the thumb of the first pair of legs of
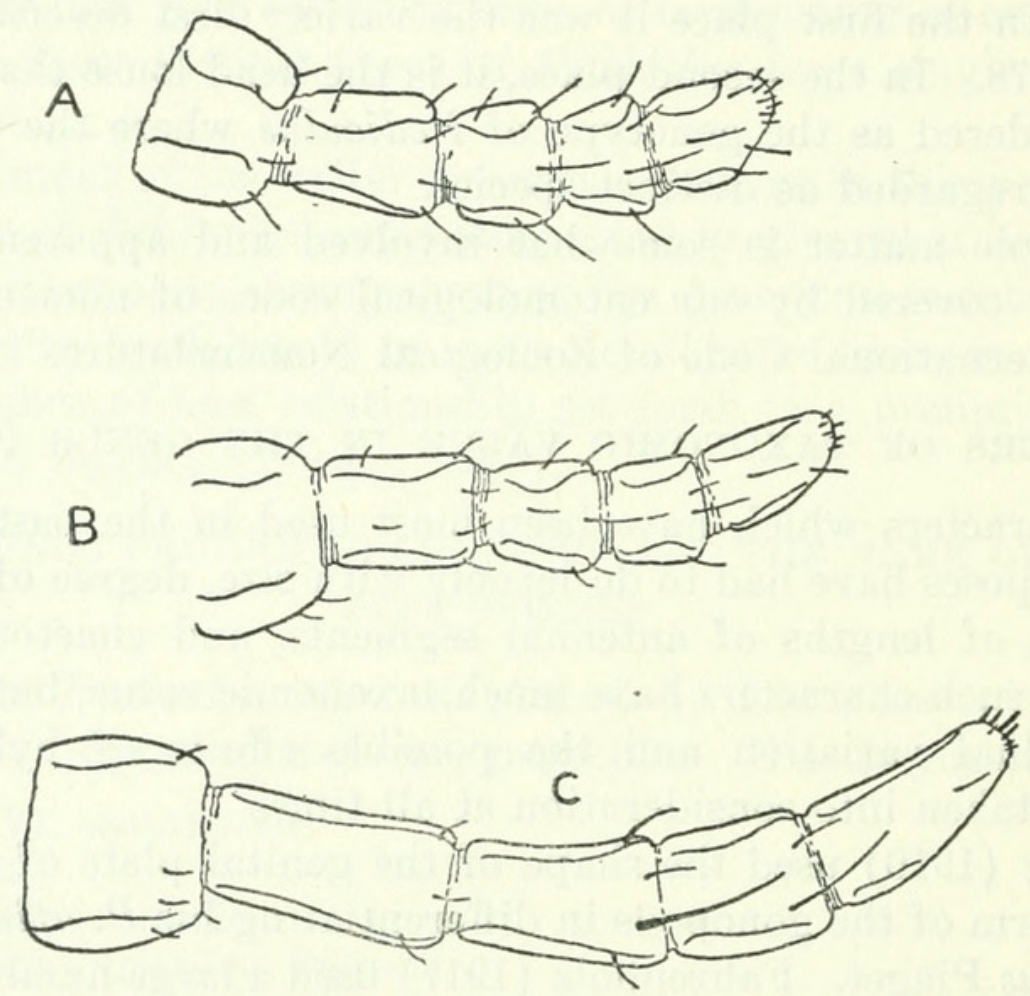

Fig. 1.-The right antenna of female from above of; A, pediculus humanus humanus linnaeus; B, pediculus humanus americanus, New variety; and, C, pediculus humanus nigritarium Fabricius. (All figures drawn to the same scale.)

the males is of much taxonomic value. The variation in the number of teeth on the claws, particularly the first tarsal claws of the male, has been used by many investigators, but I doubt that it has much real value, particularly in separating the races of lice that are found on man. This belief is in accord with Nuttall's statement (Nuttall, 1920). The number of teeth that can be observed and counted depends largely upon the degree of chitinization, and this in turn depends both on the situation in which the louse has been and the length of time that has elapsed since its last moult.

The ratio which exists between the lengths of the different segments in the antennae and the ratio existing between the length and breadth of each individual segment of the antennae is apparently constant in material which is known to be free from the possible 
influence of hybridization. Where such specimens have been examined it has nearly always been possible for the writer to divide those varieties occurring on man into two groups: One in which the antennae are relatively much longer, as in figure 1, C, and in which each segment is relatively much longer in proportion to its width, than in those of the opposite type as shown in figure 1, A and B.

The variation in the size, and to a certain extent in shape, of the thoracic spiracles and the spiracular bulbs (fig. 2) is a character of much importance in separating both species and varieties. In the head louse of Europe these spiracles are almost twice as large as they are in the head louse of American Indian mummies (see fig. 2,

$$
I
$$
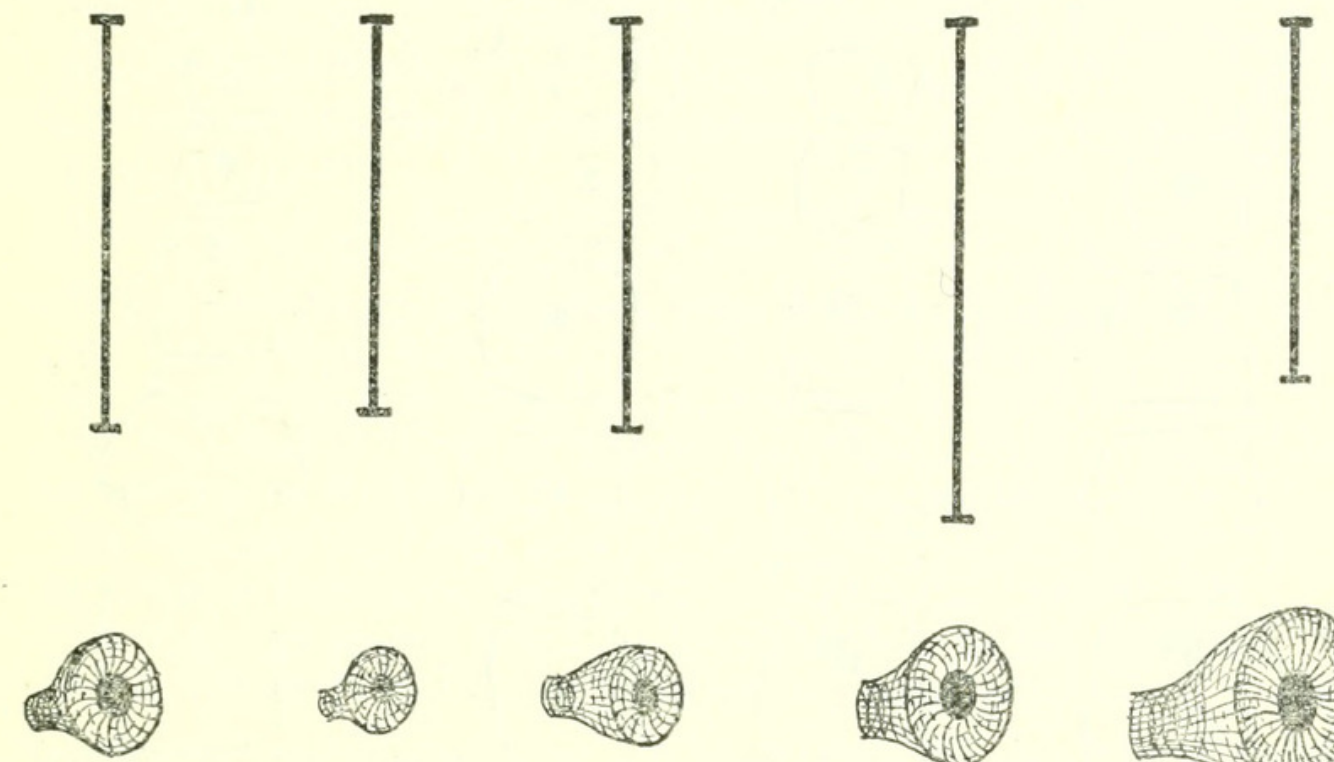

P. chapini

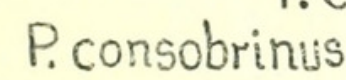

P.h.americanus

Ph.nigritarum

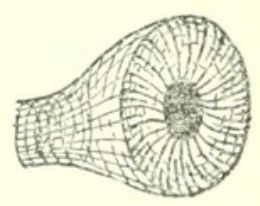

P.h.humanus

Fig. 2.-Drawings of the Right thoracic Spiracle of a female louse of five difFerent kinds of Pediculi. All enlarged, $\times 100$. The line above drawing of EACH SPIRACle RePresents the Length of the LOUSE, $\times 10$

$P$. humanus humanus and $P$. humanus americanus), yet the European head louse is a smaller louse on the average than that of prehistoric American Indians.

Dorsally, the thorax bears six large setae (macrochaetae), and the relative size of these setae is of great value in certain species. The writer finds that these setae are always present as suggested by Nuttall (1920) and never absent as claimed by Fahrenholz (1916) for one species. However, the variations in the size and positions of these setae are considerable.

Various characters have been used by different investigators and are used to a certain extent in this paper, taking into consideration the range of individual variation and the possible effect of hybridization. 


\section{POSSIBLE INBREEDING OF DIFFERENT VARIETIES OR SPECIES}

When Bacot (1917) proved that the common head louse of Europe would interbreed with the body louse of that continent and give fertile progeny, he did a most valuable service to taxonomists of the group. After a study of many lice forms collected in this country and after studying the results obtained by others in Europe, the writer is convinced that it has been hybridization that probably more that any other thing has confused different workers in attempting to apply characters that others have claimed should hold good for the lice from a given race of mankind.

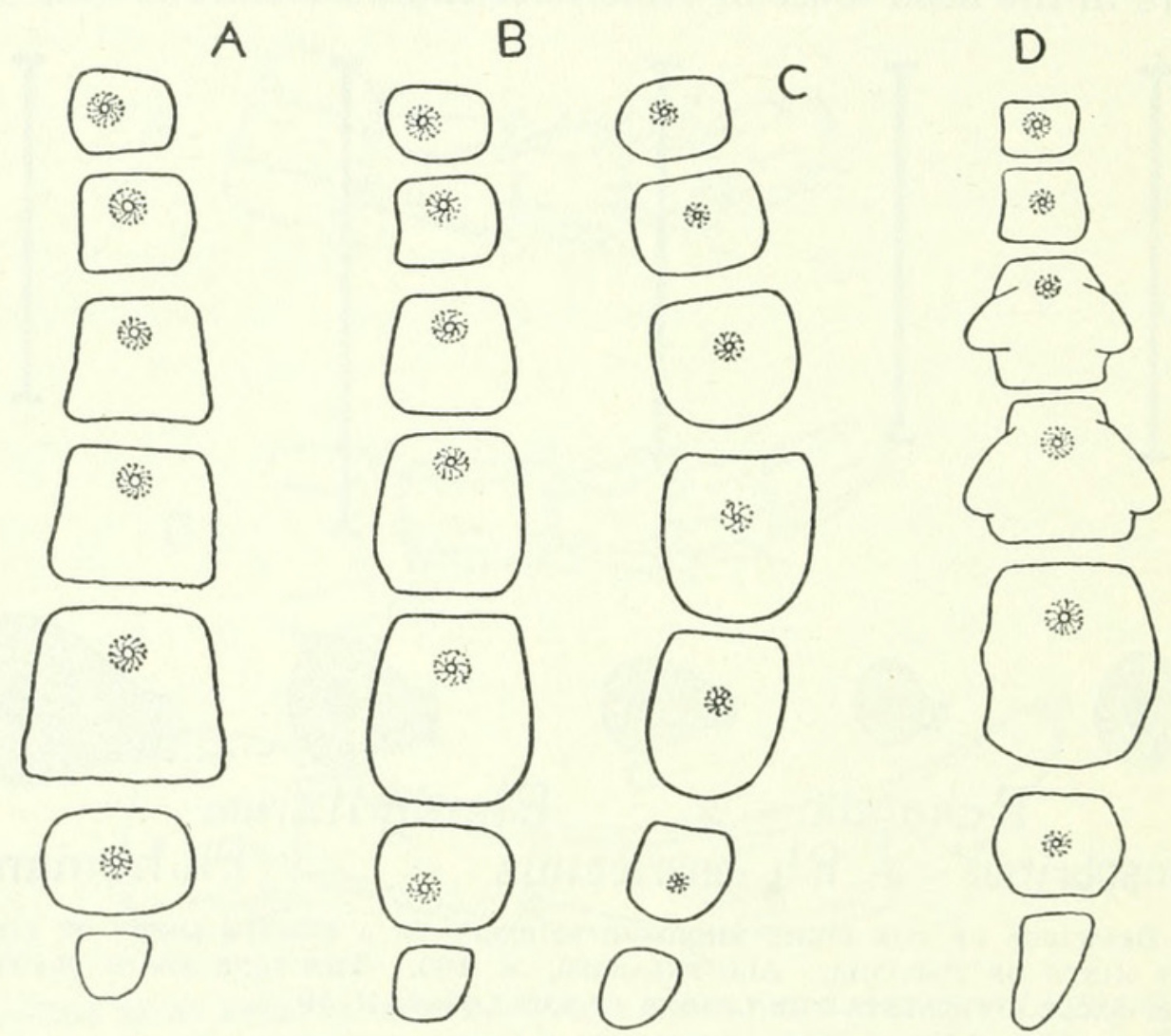

Fig. 3.-Lateral views of the right pleural plates of females of a, pediculus humanus humanus Linnaeus, from Germany; B, p. humanus americanus, new VARIETY, From INdiAN MUMMY; C, P. HUMANUS Nigritarum FABricius, From Negro in Africa; D, P. CONSOBRINUS PIAget, From Brown-hipped Marmoset

In the Americas, in parts of the Orient, and in much of Africa there has long been a mixing on a large scale of some of the primary races of men. Where this has taken place for generations it is observed how easy it would be for the different races of lice to interbreed, if such races did exist and if they could interbreed, as now Bacot has shown that two of such races do.

For this reason in the present work the writer has gone back to mummies in the case of the American Indians to find out what type of louse they harbored before the advent of the white man or the negro in the New World. 
Also material was obtained from negroes in Africa and Caucasians in Europe in order to have more assurance that the specimens studied should be really representative of the type belonging naturally to the host race on which they were found. Of course there is no real assurance that in these last two instances the lice obtained were typical for the race on which they were obtained, yet by checking up with various other records it is believed that they are very nearly typical, if no actually so.

Bacot (1917) in his breeding experiments found that some of the characters Mendelized, and, largely because of this fact, concluded that the common head louse and the body louse should be considered as distinct species. An examination of a large series of atypical lice (hybrids) presents various degrees in intergradation, these degrees becoming so fine in certain instances as to simulate a blending of characters.

\section{Genus PEDICULUS Linnaeus}

1758 Pediculus Linnaeus (part), Syst. Nat., ed, 10, p. 610.

1842 Pediculus Denny, Mon. Anop., p. 12.

1874 Pediculus Giebel, Ins. Epizoa, p. 27.

1880 Pediculus Piaget, Les Pédiculines, p. 619.

1904 Pediculus Enderlein, Zool. Anz., vol. 28, pp. 136 and 138.

1908 Pediculus Dalla Torre, Gen. Insect., Anop., p. 8.

1910 Pediculus MJöвerg, Ark. f. Zool., vol. 6, no. 13, p. 167.

1916 Pediculus Ferris, Proc. Cal. Acad. Sci., ser. 4, vol. 6, p. 136.

1919 Pediculus Nuttall, Parasitology, vol. 11, p. 334.

The genus Pediculus may be described as follows: With the characters of the family Pediculidae, and in addition, antennae distinctly segmented; legs all of the same size; in the male, the first pair of legs modified distally for clasping and in the female the hind femur provided with a posterior tubercle. Eyes conspicuous, pigmented. Abdomen elongate, segmentation marked; no lateral protuberances; pleural plates on all segments except the first. Gonopods of female conspicuous, slightly curved. Not all of the body setae arranged in transverse rows.

KEY TO SUBGENERA OF PEDICULUS

Typical pleural plates with lateral lobes; body setae rather inconspicuous and, setiform, and nearly all of them arranged into transverse rows; thoracic spiracles not conspicuous; chitinous parts usually heavily pigmented. Living on American monkeys.

Subgenus Parapediculus, new subgenus.

(Type species, $P$. consobrinus Piaget)

Typical pleural plates without lateral lobes; body setae conspicuous, frequently peglike and seldom over one-half of them arranged into transverse rows; thoracic spiracles large, conspicuous; chitinous parts frequently poorly pigmented. Living on man.

Subgenus Pediculus Linnaeus. 


\section{AMERICAN REPRESENTATIVES OF THE GENUS PEDICULUS LIN- NAEUS}

\section{PARAPEDICULUS, new subgenus}

The Pediculi of Ateles can, in general, be differentiated by using the same set of characters that are used in separating the varieties occurring on man. The writer recognizes four Atelesinfesting species, two of which are here described as new, and all of which may be keyed out as follows:

KEY TO SPECIES OF SUBgenUS PARAPEDICULUS

$\mathrm{A}^{1}{ }^{1}$ Segment VI of abdomen considerably broader and longer than $\mathrm{V}$; pleural plate $\mathrm{V}$ about one and a half times as long as IV

P. (Parapediculus) lobatus Fahrenholz.

A. ${ }^{2}$ Segment VI of abdomen not so broad as V and only slightly longer.

B. ${ }^{1}$ The inner anterior and single posterior accessory spines of tibiai thumb, or protuberance, of legs II and III equidistant from the terminal spine and neither situated in crotch of tibia; pleural plate I very small and not much larger than the inclosed stigmal foramen

P. (Parapediculus) atelophilus, new species.

B. $^{2}$ The inner anterior accessory spine of tibial thumb of leg II and III situated almost in crotch of tibia, while posterior accessory spine is situated contiguous with the chief, or terminal, spine; pleural plate I much larger, squarish and over twice the width of inclosed stigmal foramen.

C. ${ }^{1}$ Diameter of bulb of thoracic spiracle about $0.09 \mathrm{~mm}$.; posterior accessory spine of tibial thumb II and III much more slender than the inner anterior accessory spine

P. (Parapediculus) consobrinus Piaget.

C. ${ }^{2}$ Diameter of bulb of thoracic spiracle about $0.06 \mathrm{~mm}$.; posterior accessory spine of tibial thumb II and III subequal with the inner anterior accessory spine

P. (Parapediculus) chapini, new species.

\section{PEDICULUS (PARAPEDICULUS) LOBATUS Fahrenholz}

Plate 2, figure 5

1913 Pediculus lobatus Fahrenholz, Zool. Anz., vol. 41, p. 373 (no description).

1917 Pediculus lobatus Fahrenholz, Zool. Anz., vol. 48, p. 89.

1919 Pediculus humanus, race capitis Nuttall, Parasitology, vol. 10, pp. 337, 340.

1920 Pediculus humanus, race capitis Nuttald, Parasitology, vol. 12, p. 142.

Female.-Head with well-developed neck region; forehead swollen, being broader at about its middle than at its base. Antennae shorter than head. Macrochaetae of thorax unequal, the middle pair longer than the others; machrochaeta I about one-third as long as the width of the first coxa; macrochaeta III situated about the diameter of the bulb of thoracic spiracle behind the same. Abdomen rather short and very broad at the sixth segment, which is much broader than any other segment and almost twice as long as seg- 
ment V. Setae of abdomen nearly all arranged in transverse rows, none is peg-like. Pleural plates in the single female observed not sufficiently hardened for description. Legs moderate.

Length of female newly formed and with adhering nymphal skin, $1.83 \mathrm{~mm}$.; width, $0.88 \mathrm{~mm}$.

Male.-Not observed by the writer. Fahrenholz gives only the following sentence in regard to the male in his original description: "o mit zweiteiliger Genitalplatte (wie bei P. capitis maculatus)."

Length, 1.89-2.19 mm. (Fahrenholz); width, 0.82-0.97 mm. (Fahrenholz).

Type host and type locality.-The host is Schlegel's spider monkey, Ateles pan. Type locality?

Type.-Deposition of type not known to writer.

Material examined consists of a single female not yet emerged from her nymphal skin, many nymphs, and eggs. All of these were obtained from a skin (U.S.N.M. 61284) of Ateles pan, the monkey having been taken in Guatemala.

This species is very distinct from all the others of its subgenus and genus in the great development of segment VI (see fig. 5, pl. 2), which protrudes conspicuously at the sides of the abdomen far beyond the other segments.

In Fahrenholz's description of lobatus he writes that the six large setae (macrochaetae) of the thorax are wanting. Nuttall (1920, p. 148) says that he firmly believes, "that they were merely overlooked by being viewed through balsam." The writer finds that Nuttall is correct in this belief. However, it should be added that the macrochaetae of the thorax in this species are much smaller than they are in $P$. humanus.

\section{PEDICULUS (PARAPEDICULUS) ATELOPHILUS, new species}

Figs. $4 \mathrm{~A}$ and 5

Female.-Unknown.

Male.-Head with neck very distinct; a slight tubercle behind each eye; forehead dome-shaped, being very slightly swollen. Antennae about as long as head; segment I almost twice as broad as long; segment II about one and two-thirds times as long as broad and almost equal to III plus IV; segment III slightly longer than broad and slightly longer than IV; segment IV equally long and broad; segment $\mathrm{V}$ about one-third longer than broad and shorter than II. Macrochaetae of thorax almost subequal; macrochaeta I about onehalf as long as the width of coxa I; macrochaeta III situated about the diameter of thoracic spiracular bulb behind the same. Posterior marginal setae of thorax rather small, but there are at the lateral extremes of the posterior thoracic margin three larger, subequal setae. 
Thoracic spiracles medium, situated dorso-laterally. Abdomen with well marked segmentation; all the larger setae arranged in transverse rows. Pleural plates well chitinized and almost black; pleural plate I (fig. 4,A) small, almost circular, scarcely twice the diameter of the spiracular bulb it contains; pleural plate II squarish, not lobed; pleural plate III smaller than IV but with very distinct lateral lobes; pleural plate IV with large and conspicuous lateral lobes but not so long as V; pleural plate $\mathrm{V}$ the longest of all the plates but only slightly lobed laterally; pleural plates VI and VII without lateral lobes. Legs moderate; femur III almost twice as long as broad, tibia III about two and a half times as long as broad.

Length, $2.15 \mathrm{~mm}$.; width, $0.80 \mathrm{~mm}$.

Type host and type locality.-Ateles geoffroyi (gray form, or melanochir type of coloration); type locality?

\section{Type.-Cat. No. 28105 , U.S.N.M.}

This species differs from the others particularly in the characters given in the preceding key. Described from a male specimen taken from the skin of Ateles geoffroyi (U.S.N.M. 155393). This Ateles skin is from one of several specimens kept some years ago at the National Zoological Park. Three of the skins are marked almost exactly alike (grey type, with black on head, hands, feet, elbows, and knees). The writer has noted infested living specimens of Ateles geoffroyi in the National Zoological Park, but has never had the opportunity of examining any of their lice.

In addition to the male specimen mentioned the writer has obtained nits from skins of Ateles geoffroyi as follows: From skin (U.S.N.M. 12150), taken at Talamanca, Costa Rica, by W. M. Gabb; from skin (U.S.N.M. 12151) taken at the same place by the same collector; from skin (U.S.N.M. 61209) taken in Costa Rica and from skin (U.S.N.M. 154223) (locality and collector ?).

\section{PEDICULUS (PARAPEDICULUS) CONSOBRINUS Piaget}

Plate 1, figs. 1 and 2 ; text figs. 2 and $3 \mathrm{D}$

1880 Pediculus consobrinus Piaget, Les Pediculines, p. 626, pl. 51, fig. 4. 1908 Pediculus consobrinus Dalla Torre, Gen. Ins., Anop., p. 8. 1910 Pediculus affinis MJöвеRg, Ark. f. Zool., vol. 6, no. 13, p. 169, fig. 85. 1911 Pediculus consobrimus Neumann, Arch. Par., vol. 14, p. 412.

1913 Pediculus consobrinus Fahrenholz, Zool. Anz., vol. 41, p. 372.

1916 Pediculus mjöbergi Ferris, Proc. Cal. Acad. Sci., ser. 4, vol. 6, p. 136. 1919 Pediculus humanus Nuttall (in part), Parasitology, vol. 11, p. 334.

Female.-Head rather short; neck scarcely differentiated and poorly chitinized, the ocular plates stopping abruptly and bearing a low tubercle at their posterior margins; forehead short, about twice as broad as long. Antennae about equal to the head in length; 
segment I almost twice as broad as long; segment II about one and a third times as long as broad and but slightly longer than III; segment III longer than broad and longer than IV; segment IV scarcely as long as broad; segment $\mathrm{V}$ short, only slightly longer than broad. Macrochaetae of thorax medium, I and II subequal, III slightly smaller; macrochaeta I slightly longer than the width of coxae I; macrochaeta III situated about the diameter of bulb of thoracic spiracle behind the same. Posterior marginal setae of thorax, 7-9 on each side, including a larger submedian pair and

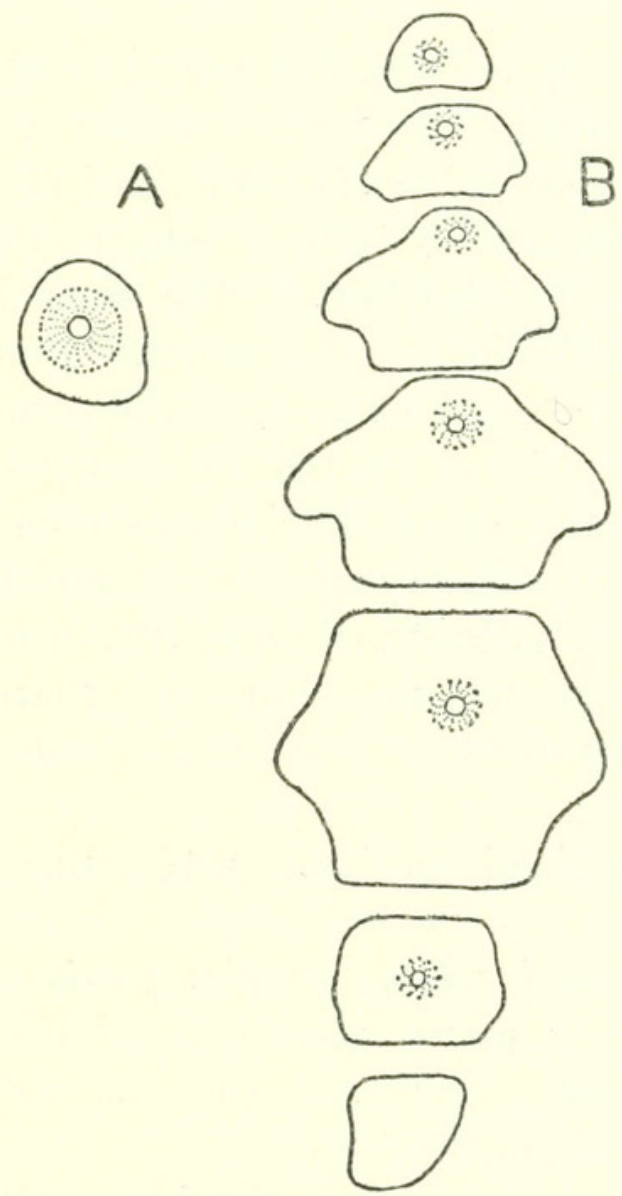

Fig. 4.-A, Lateral view of first pleural plate of right side of male of pediculus (PARAPEDiculus) ATElophilus, NEW SERies; B, lateral VieW OF Right Pleural plates of Female of pediculus (Parapediculus) Chapini, NeW Species

three larger, subequal setae near the corner of thorax. Thoracic spiracles rather small, diameter of bulb $0.089 \mathrm{~mm}$., more dorsal than lateral in position. Abdomen large; segment VI longer than V but not so broad; all the abdominal setae except the minute hairs arranged strictly in transverse rows; transverse row on ventral surface of segment VI with 10-11 setae which extend scarcely half way to posterior margin of segment, flanking pair of setae slightly larger than those in row, discal setae few, minute hairs. Pleural plates (fig. 3, D) large, conspicuous; pleural plate I squarish, over twice as long as diameter of stigmatic bulb; plate II squarish, about as broad as I but much longer; plate III very much larger than II 
and with large, conspicuous lateral lobes; plate IV larger than III and with larger lateral lobes; plate $\mathrm{V}$ much the largest of all the pleural plates, with or without very small lateral lobes; plate VI broader than long and without lateral lobes; plate VII triangular, longer than broad. Legs of medium length; femur I only slightly longer than broad; tibia I over twice as long as broad. Posterior tubercle of femur III large, with a deep emargination next to it on the inside, bearing a seta near tip longer than tubercle itself.

Length of an average-sized, unengorged female, $3.15 \mathrm{~mm}$.; greatest width, $1.30 \mathrm{~mm}$.

Male.-Leg I slightly enlarged; femur I slightly longer and tibia I slightly shorter than in the female; tarsus I enlarged. Setae on anterior tibial thumb as follows: Chief or distal spine extending beyond the margin of thumb by half its length; dorsal accessory spine about half as thick as distal one, of the same length, and situated less than its own width inside of terminal spine; outer ventral accessory spine setiform, twice as long as the terminal spine and situated directly below it; inner ventral accessory spine slightly longer than terminal spine and about one-half as broad, situated considerably inside the other accessory spines but not in the crotch of the tibia. Pleural plates similar to those of female except for I and III; I is irregular in shape and much broader than long, III has low, small lateral lobes instead of the conspicuous ones found in the female.

Length of average-sized specimen, $2.45 \mathrm{~mm}$; greatest width, 0.90 $\mathrm{mm}$.

Type host and type locality.-Ateles paniscus from (?).

Described from very many specimens of both sexes taken from "post-mortem" specimen of host species, Ateles paniscus (U.S.N.M. 238254), collected at Beni, Bolivia.

In 1922 Dr. W. M. Mann brought back with him from South America two red-faced spider monkeys (A. paniscus) that were grossly infested with $P$. consobrinus. The monkeys were presented to the National Zoological Park, but within a few days one of them died. This specimen was "pickled" in a large jar where the writer observed that it was loaded with thousands of lice in all stages of development, and the hairs of the host in all parts of its anatomy contained countless numbers of nits. The other individual received several treatments for lice at the zoological park but died within a few weeks.

Doctor Mann also brought back with him two living examples of the brown-hipped marmoset (Lenotocebus nigricollis), obtained at Tumupasa, Bolivia. These were placed in the National Zoological Park, but lived only a few days. When they died they showed a slight infestation with a Pediculus, species, and nits in some abun- 
dance were present. These Pediculids appear to agree in all respects with those from Ateles paniscus, hence the writer is of the opinion that the lice iepresented stragglers on the marmosets notwithstanding they had lived for some days on this peculiar host.

Mjöberg (1910) described as new his Pediculus affinis from an undetermined species of Ateles. Later (1916) Ferris gave a new name to this louse, that of mjöbergi, since affinis was preoccupied. When the present writer compared the specimens of pediculi from Ateles paniscus with Piaget's description and figures considerable disagreement was found. When compared with Mjöberg's description and figure almost perfect agreement was noted. Both Piaget and Mjöberg give a detailed drawing of the ventral side of the last segments of the female, showing the genital plate and gonopods. I find that in the specimens I have studied the genital plate and the gonopods are as Mjöberg figures them, as is shown on photograph (pl. 1, fig. 2). Not only this but the smaller differences mentioned
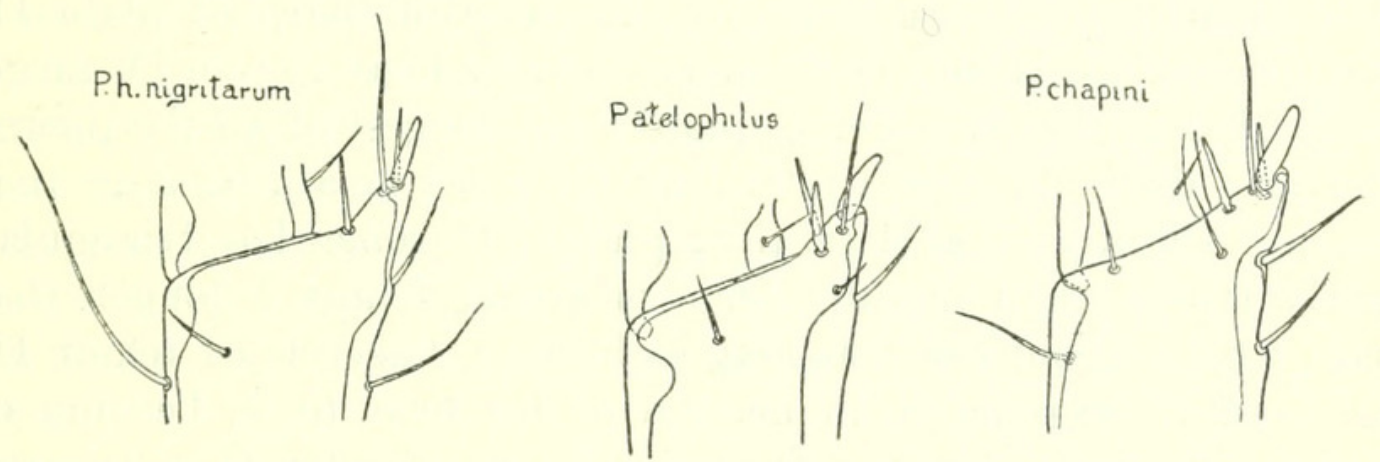

Fig. 5. - A NTerior view of distal end of leet hind tibia of males of three species of pediculus, All dRAWN to the same scale

by Mjöberg between his affinis and Piaget's consobrinus I find do not hold when specimens from the type host of consobrinus are examined. It appears that the drawing given of the genital plate and gonopods by Piaget were made from a specimen that was somewhat shriveled (as most balsam mounts are). This would particularly account for the strongly-curved, sharp-pointed gonopods as figured by Piaget. I do not believe that gonopods of such a shape exist anywhere in the genus Pediculus.

This large louse is very typical of the subgenus Parapediculus, and quite diflerent from the head louse of man as noted by Piaget, Mjöberg, and others.

\section{PEDICULUS (PARAPEDICULUS) CHAPINI, new species}

Plate 1, figs. 3 and 4 ; text figs. $2,4 \mathrm{~B}, 5$

Female.-Head with poorly developed neck region; postocular tubercle rather pronounced; forehead about twice as broad as long, slightly swollen. Antennae about as long as head; segment I almost twice as wide as long; segment II about one and a half times as long 
as broad; segment III distinctly longer than broad and longer than IV; segment IV about as broad as long; segment V only slightly longer than broad and equal to III in length. Macrochaetae of thorax medium, subequal; macrochaeta I about two-thirds as long as the width of coxa I; macrochaeta III situated slightly more than the diameter of the bulb of thoracic spiracle behind the same. Posterior marginal setae of thorax about 6 or 7 on each side, a larger pair near the median plane and three large pairs situated laterally. Thoracic spiracles the smallest of any species of the genus observed by the writer, being $0.062 \mathrm{~mm}$. in diameter across the bulb. Abdomen large and long, segment VI slightly longer and slightly narrower than V. Body setae small and hard to see, all the larger ones arranged in transverse rows. Number of setae in transverse row on ventral side of segment VI typically 10. Pleural plates (fig. 4, B) yery long and very broad; pleural plate I broader than long and slightly lobed laterally; plate II very broad, distinctly lobed laterally and with spiracle almost touching the anterior margin; plate III much longer than II and much more strongly lobed; plate IV larger than III but of the same shape; plate $V$ the largest of all the pleural plates and distinctly lobed laterally; plate VI small, broader than long, and slightly lobed laterally; plate VII somewhat triangular, slightly longer than broad. Legs medium; femur I longer than broad; tibia I about twice as long as broad. Tubercle of femur III large, with a deep notch in margin of leg next to it, bearing on anterior side some distance from tip a seta shorter than tubercle itself.

Length of an average-sized, unengorged female, $2.95 \mathrm{~mm}$.; greatest width, $1.35 \mathrm{~mm}$.

Male.-Leg I about the same length as the others but with the tibia shorter and stouter and the tarsus slightly enlarged. Distal, or chief, spine of thumb of tibia I extending beyond the margin of thumb by a little over one-half its length; outer anterior accessory spine very sharp, about one-half as broad as the distal spine and as long as the same; inner anteror accessory spine subequal with outer anterior accessory spine and situated almost in the crotch of the tibia; ventral or posterior accessory spine long, setiform, about twice as long as the distal spine. Pleural plates smaller but similar to those of female, the first one somewhat differently shaped from the first plate of the female, being broader in proportion to its length and more irregular.

Length of average-sized specimen, $2.45 \mathrm{~mm}$; width, $0.95 \mathrm{~mm}$.

Type host and type locality.-Ateles ater, from?

Type slide.-Cat. No. 28106, U.S.N.M.

Described from many males and females taken by Dr. E. A. Chapin from an individual of Ateles ater which died in the National 
Zoological Park in 1921. Nits were taken from skin (U.S.N.M. 200153) of Ateles ater and also from skin of young male of Ateles ater from Brazil which died in Washington, July 24, 1915.

This species is closely related to $P$. (Parapediculus) consobrinus Piaget, but differs from Piaget's species in having a much smaller thoracic spiracle, pleural plates smaller, more strongly lobed, and of a different shape (see figs. $3, \mathrm{D}$ and $4, \mathrm{~B}$ ), particularly is this true of pleural plates II and V.

\section{Subgenus PEDICULUS LinnaEUS}

In America it is difficult to obtain representatives of man-infesting pediculi that are typical of the different forms which originally inhabited the different races of men. This has caused the present writer much inconvenience in revising the genus for the New World, but it may be that as a result of this inconvenience and its attendant delay a much better conception and a much more accurate knowledge have been obtained in regard to the lice types of mankind. All forms occurring on man are here regarded as varieties of the Iinnaean species, Pediculus humanus. This is done largely because the writer has been unable to determine just what type of louse is represented by the corporis of De Geer. Undoubtedly many of the body lice of America and Europe are hybrids between the Cancasian head louse of man and some other type of head or body louse.

The five varieties of Pediculus humanus which the writer can recognize in our American fauna are keyed out as follows:

A. ${ }^{1}$ Over one-half of the body setae arranged into definite transverse rows, those that are not so arranged chiefly setiform; number of setae in ventral row on segment VI of female typically 8 ; diameter of bulb of thoracic spiracle less than a tenth of a millimeter; macrochaetae of thorax shorter.

B. ${ }^{1}$ Second and fifth antennal segments each twice as long as broad and segment III broadened distally and distinctly longer than IV.

C. ${ }^{1}$ Second pair of macrochaetae of thorax longer than the others; macrochaeta III of thorax situated about the diameter of the thoracic spiracle behind the same

P. (Pediculus) humanus nigritarum Fabricius.

P. (Pediculus) humanus corporis De Geer.

C. $^{2}$ Second pair of macrochaetae of thorax subequal with others; macrochaeta III of thorax situated more than the diameter of thoracic spiracle behind the same

P. (Pediculus) humanus marginatus Fahrenholz.

B. ${ }^{2}$ Second and fifth antennal segments each about one and a half times as long as broad and segment III subequal or almost subequal with IV P. (Pediculus) humanus americanus, new variety. 
A. ${ }^{2}$ Scarcely half of the body setae arranged into definite transverse rows, those that are not so arranged are spinelike or peglike; number of setae in ventral row on segment VI of female typically 12 (11 to 13); diameter of spiracle bulb considerably over a tenth of a millimeter

P. (Pediculus) humanus humanus Linnaeus.

\section{PEDICULUS (PEDICULUS) HUMANUS NIGRITARUM Fabricius}

Plate 2, figs. 6 and 7 ; text figs. 1c, 2, 3c, 5, 6

1805 Pediculus nigritarum FABricius, Systema Antliatorum, p. 340.

1816 Pediculus nigrescens OLfERs, De vegetativis et animatis corporibus in corporibus anincatis reperiundis commentarius. Pars I, p. 81. Berlin (Reference from Fahrenholz, work not seen by writer).

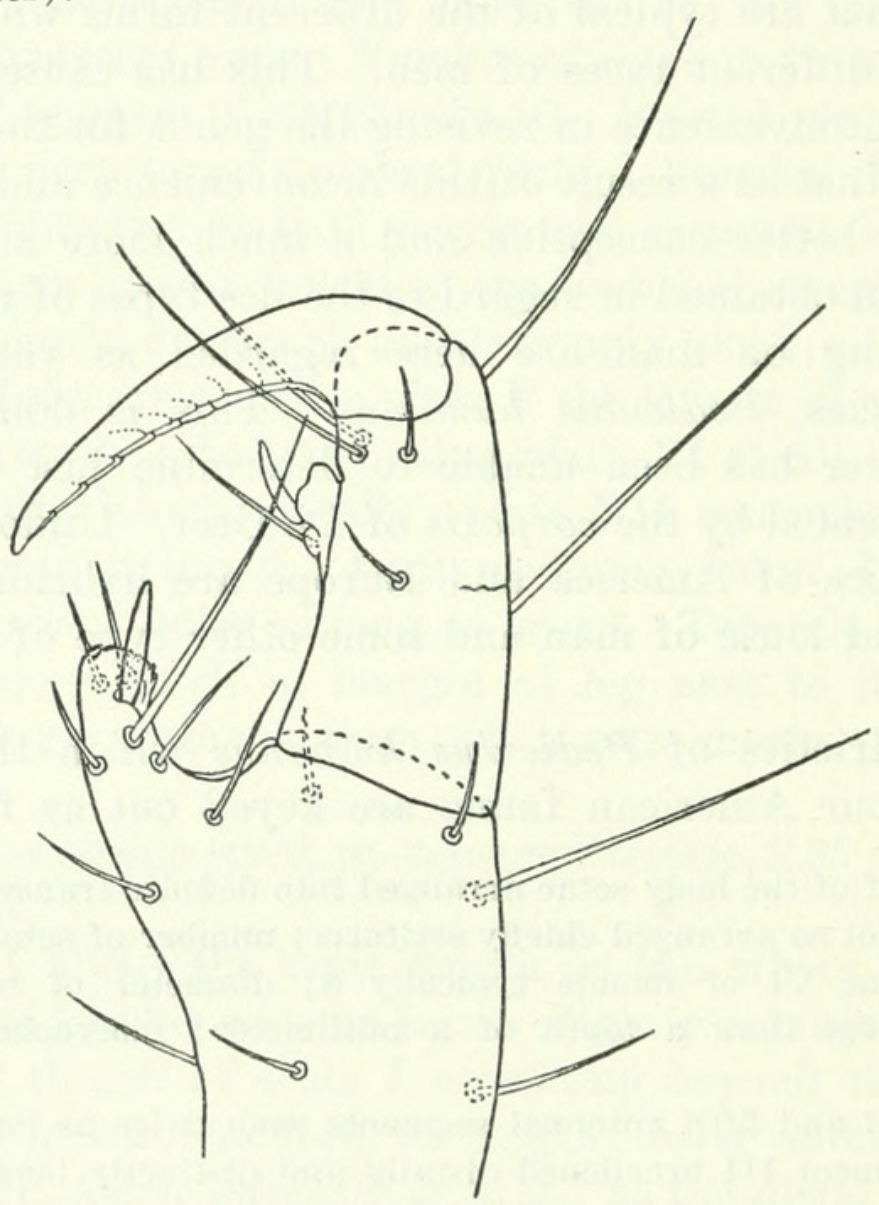

Fig. 6.-Ventral view of end of Left ANTERior Leg of MAle of pediculus (Pediculus) HUMANUS NIGRITARUM FABRICIUS

Female.-Head about as broad as long; forehead about twice as broad as long, not swollen; eyes less conspicuous than in most forms of Pediculus; postocular tubercle reduced. Antennae equal to or slightly surpassing the head in length; segment I frequently as long as or longer than broad; segment II twice as long as broad but not as long as III plus IV; segment III decidedly broadened distally and about one and a half times as long as broad; segment IV scarcely at all broadened distally, slightly longer than broad and shorter than III; segment V about twice as long as its width at the base and equal in length to segment II. Macrochaetae of thorax 
medium in length, II slightly longer than I and III; macrochaeta I about two-fifths as long as width of coxa I; macrochaeta III about the diameter of thoracic spiracle behind the same. Posterior marginal setae of thorax typically six on each side, all spinelike but the outer one and the third from the outer end of row very minute. Thoracic spiracles medium, spiracular bulb $0.110 \mathrm{~mm}$. in diameter. Abdomen very large and in case of some females much distended by developing egg; most of abdominal setae in transverse rows, the dorsal ones two or three times as long as the ventral ones; setae in transverse row on ventral side of sixth abdominal segment typically 8 but varying from 7 to 9 . Pleural plates usually rather poorly chitinized and poorly pigmented; plate I broader than long and not squarish; plate II broader than long and squarish, spiracle situated slightly in front of the middle; plate III about equal in length and breadth, spiracle slightly in front of middle; plate IV the largest of all the pleural plates, longer than broad and slightly broader than III; plate $\mathrm{V}$ as long as IV but not so broad; plate VI small, spiracle behind the middle; plate VII almost circular, but varying much in shape. Legs slender; femur I about one and a half times as long as broad; tibia I about two and a half times as long as broad. Tubercle of femur III varying in size, low, usually only a slight notch in leg inside of tubercle, seta on tubercle about twice as long as tubercle itself.

Length of an average-sized, unengorged female, $3.80 \mathrm{~mm}$.; greatest width, $1.40 \mathrm{~mm}$.

Male.-Leg I stouter than in female with thumb much larger; tibia I about twice as long as broad; distal, or chief, spine of thumb of tibia I not extending beyond the margin of the thumb by half its length; outer, anterior accessory spine setiform, almost three times as long as the terminal spine itself; inner anterior accessory spine rather slender and slightly longer than the terminal spine; posterior accessory spine almost setiform, being much smaller but about as long as the inner anterior accessory spine. Chaetotaxy of distal end of left hind tibia (fig. 5) as follows: Distal, or chief, spine extending beyond the tip of margin of process by about three-fourths its length; outer, anterior accessory spine about two and a half times as long as distal spine; inner, anterior accessory spine about as long as distal spine and situated in crotch of tibia; posterior accessory spine longer than distal spine and about as stout as the inner, anterior accessory spine. Pleural plates not essentially different from those of the female, plate I appears to be a little more irregular in shape and somewhat smaller than in the female. 
Length, $3.00 \mathrm{~mm}$.; width, $1.05 \mathrm{~mm}$.

Type host and type locality.-African negro, in Africa (?).

This description is based on females and males collected from negroes in Africa by H. C. Raven of the Smithsolian-Universal African Expedition of 1919-1920. Of the American specimens of Pediculus examined by the writer those of a lot taken by R. H. Hutchinson at New Orleans, Louisiana, May 1, 1918, should be referred to this variety. I find them almost identical with the material taken from negroes in Africa. Most of the body lice found in North America appear to be impure races or hybrids.

\section{PEDICULUS (PEDICULUS) HUMANUS CORPORUS De Geer}

1758 Pediculus humanus Linnaeus (part), Syst. Nat., ed. 10, p. 610.

1766 Pediculus humanus, variety 2 Linnaeus, Syst. Nat., ed. 12, vol. 2, p. 1016.

1778 Pediculus humanus, variety corporis De GEer, Mem. Hist. Ins., vol. 7, p. 67, pl. I, fig. 7 .

1818 Pediculus vestimenti Nitzsch, Germar's Mag., vol. 3, p. 305.

1842 Pediculus, vestimenti Denny, Mon. Anop., p. 16, pl. 26, fig. 1.

1874 Pediculus vestimenti Giebel, Ins. Epizoa, p. 27, pl. 1, fig. 5.

1850 Pediculus vestimenti Piaget, Les Ped., p. 623, pl. 50, fig. 3.

1908 Pediculus corporis Dalla TorRe, Gen. Ins., Anop., p. 8.

1910 Pediculus vestimenti MJöBerg, Ark. f. Zool., vol. 6, no. 13, p. 168.

1911 Pediculus capitis, variety vestimenti Neumann, Arch. de Par., vol. 14, p. 411.

1912 Pediculus corporis Fahrenholz, 2-3-4th Jahresb. d. Niedersäch. Zool. Ver., p. 2, fig. 2, pl. 3, figs. 1-2.

1913 Pediculus corporis Fahrenholz, Zool. Anz., vol. 41, p. 373.

1916 Pediculus corporis FerRis, Proc. Cal. Acad. Sci., ser. 4, vol. 6, p. 137. 1917 Pediculus humanus (vestimenti) Васот, Parasitology, rol. 9, p. 255. 1919 Pediculus humanus, race corporis Nuttall, Parasitology, vol. 11, p. 334.

1920 Pediculus humanus, race corporis Nuttall (part), Parasitology, vol. 12, p. 151.

No attempt is here made to describe the body louse of Europe or of the Caucasian race. Up to the present the writer has been unable to get material which could be considered as truly representative of the form described by Linnaeus and by De Geer and other early entomologists. Indeed, if such forms were available for study there would probably be but little assurance that they were free from hybridization. That the ancient Mediterranean peoples had contacts with negroes and, in the case of the Egyptians, had many negro slaves is well known. Theoretically, at least, there should have been no reason why the body louse of the negro should not have spread to the Hebrews, Greeks, Phoenicians, and others.

De Geer (1778) figures his $P$. humanus corporis as being very much like his $P$. humanus capitis, so much so in fact that one is inclined to wonder if he really had the typical European body louse or one of the hybrids from the head louse of that continent. A 
closer inspection of his figures (pl. I, T. VII) shows that his variety capitis has the abdominal segments more clearly demarcated, the pleural plates pigmented, the neck region more distinct and the thorax flatter than in his variety corporis. Although these characters are quite variable and not strictly reliable for separating most of the body lice that are found on white people from the typical European head louse, yet they do indicate that what he was dealing with was a variety very similar in certain respects to the forms mentioned by others as the body louse of Europeans.

Some of the American body lice are similar to the head louse of Europe, others are similar to the Indian head-louse type, and yet others show affinities with the body louse of Africa. In these forms there are found almost all degrees of intermediate characters, be they the shape of antennal segments, shape of neck region, chaetotaxy, size of thoracic spiracle, or any one of several other structures.

Judging from the literature and from observations on many body louse hybrids, the corporis of De Geer was a smaller louse than $P$. humanus nigritarum, and also it had the discal setae of the abdomen more numerous and more peglike; the segments of the antennae were hardly as long and were of more uniform width.

It is highly probable that a race of $P$. humanus capitis spread to the body from the head as the habit of wearing clothes developed among the Caucasians. It is stated that some races of man when they were yet uncivilized had no body lice, but when a certain amount of clothes-wearing was practiced and contacts with white man were made they became infested with body lice in addition to the head lice.

\section{PEDICULUS (PEDICULUS) HUMANUS ANGUSTUS Fahrenholz}

1915 Pediculus capitis angustus Fahrenholz, Zeit. f. Morph. u. Anthro., vol. 17, p. 597.

1915 Pediculus capitis marginatus Fahrenholz, Zeit. f. Morph. u. Anthro., vol. 17 , p. 599.

1917 Periculus hunianus marginatus Fahrenholz, Zool. Anz., vol. 48, p. 87. 1917 Pediculus humianus chinensis Fahrenholz, Zool. Anz., vol. 48, p. 87. 1917 Pediculus corporis angustus Fahnenholz, Zool. Anz., vol. 48, p. 88. 1919 Pediculus humanus, race capitis NutTall (part), Parasitology, vol. 11, p. 334 .

1920 Pediculus humanus, race capitis NutTall (part), Parasitology, vol. 12 , p. 152.

Female.-Only hybrid or racially impure females observed.

Male.-Head longer than broad, yet with poorly developed neck; forehead long, two-thirds as long as broad and with sides much more heavily chitinized than the temples; postocular tubercles low. Antennae (broken in two specimens observed and last two segments wanting) of the type of corporis; first segment slightly broader than long and broadest at its base; second segment twice as long as broad and broadened distally; third segment one and a half times as long 
as broad. Macrochaetae of thorax subequal, macrochaeta I equal to about one-half of the width of coxa I; macrochaeta III more than the diameter of thoracic spiracle behind the same. Posterior marginal setae of thorax typically eight on each side, the two nearest the median line and the two nearest the lateral margin of the body much larger than the others. Thoracic spiracles medium sized, diameter of bulb $0.091 \mathrm{~mm}$. Abdomen of typical shape for the genus; setae varying much in size, nearly all of them in transverse rows and but few of them spinelike, or peglike. Pleural plates similar to those of corporis or americanus; plate I about twice as broad as long. Legs long; femur I twice as long as broad; thumb of tibia I very long, being almost as long as the tibia itself. Chaetotaxy of thumb of tibia I: Chief spine swollen about its middle and attenuated distally, extending beyond the margin by almost exactly one-half its length; anterior accessory spine very slender and situated more on the inner than the anterior margin of the thumb; outer posterior accessory spine a long seta over twice as long as the chief spine; inner posterior spine very slender, setiform and situated inside of the anterior accessory spine.

Length, $3.40 \mathrm{~mm}$; greatest width, $1.25 \mathrm{~mm}$.

Type host and type locality.-Japanese race. Type locality (?)

This description is based upon two males taken at Shuin Gien Su (elevation, 1,200 feet), south of Suifu, Szechuan, China (probably from a Chinaman), May 10, 1924, collected by D. C. Graham.

The most characteristic thing about this variety (according to characters of two specimens examined) is the small size of the accessory spines on the thumb of tibia $I$ and the rather extreme length of segments II and III of the antennae. This louse probably infests the head chiefly, but to a certain extent the body also. It has not been shown in the case of the yellow race of mankind or the red race that a distinctive body louse developed apart from the type found on the head.

Undoubtedly the Chinese race of Pediculus humanus has been brought to America with the influx of Orientals. The nearest approach to an authentic record for this variety from America which the writer has obtained is a lot of 2 females and 1 male taken by Dr. L. Stejneger (No. 1743) in 1882 from an Aleutian Eskimo at Bering Island. These lice appear to be hybrids.

PEDICULUS (PEDICULUS) HUMANUS AMERICANUS, new variety

Plate 3, figs. 9, 10, 11; text figs. 1B, 2, 3B

Female-Head with very poorly developed neck region; forehead by no means twice as broad as long; postocular tubercle low. Antennae medium in length and not as long as head; segment I almost twice as broad as long; segment II almost one and a half 
times as long as broad; segment III as broad as long and longer than IV; segment IV broader than long; segment $\mathrm{V}$ about one and a half times as long as broad; segments II, III and IV broadest at distal ends. Macrochaetae of thorax moderate; second pair slightly longer than the other two; macrochaeta I slightly less than one-half as long as the width of coxa I; macrochaeta III situated about the diameter of thoracic spiracle behind the same. Thoracic spiracles rather small, diameter of spiracular bulb 0.080 mm. Abdomen with sharp divisions between segments; about half of the setae of abdomen are arranged in transverse rows, those that are not in rows are smaller; number of setae in transverse row on ventral side of sixth abdominal segment from 7 to 9 , average 8 (of 10 females examined 8 had 8 setae in this row). Pleural plates similar to those of humanus humanus but less squarish, although there is much variation in their shape. Legs medium in length and stoutness; femur I about one and a third times as long as broad; tibia I fully twice as long as broad. Tubercle on femur III large, its seta not as long as the tubercle itself. In americanus there is a tendency for all the femora to have a posterior tubercle, but those on femora I and II are never conspicuous like the tubercle on femur III.

Length of average sized, unengorged female, $3.15 \mathrm{~mm}$; greatest width, $1.00 \mathrm{~mm}$.

Male.-Leg I stouter than in female. Thumb of tibia I with spines as follows: Chief spine extending less than one-half its length beyond the margin of the thumb; anterior accessory spine situated but slightly nearer the inner than the outer margin of thumb and not extending beyond the margin; outer posterior accessory spine long, somewhat setiform, and situated as near the outer margin of the thumb as the chief spine itself; inner posterior spine large, about two-thirds as broad as chief spine but longer and situated back from the inner margin of the thumb. Pleural plates similar to those of female, plate I usually somewhat smaller and broader in proportion to its length. Femur III showing a slight tubercular swelling on posterior margin.

Length, $2.65 \mathrm{~mm}$; greatest width, $0.80 \mathrm{~mm}$.

Type host and type locality.-American Indian mummy from Surco, Peru.

Type (paratype).-Cat. No. 28107, U.S.N.M.

Described from males and females taken from the scalps of American Indian mummies loaned by the American Museum of Natiral History through the courtesy of Dr. Frank E. Lutz. Holotype (a female, deposited in American Museum of Natural History) taken from hair of head of mummy $\frac{\mathrm{B}}{1342}$, Surco, Peru; nymphs and nits 
also were obtained from same hair sample. Other mummy lice material examined as follows: Abdomen of female and first nymphal instar (dissected from nit) taken from mummy B-4710, Ancon, Peru; 5 males, 11 females and numerous nymphs in various stages of development, as well as nits from mummy $\frac{G}{404}$, Canyon del Muerto, New Mexico. Also nits were obtained from the following hair samples from the heads of Indian mummies from the American Museum of Natural History $\frac{41.0}{3395}, \frac{\mathrm{B}}{4558}, \frac{\mathrm{B}}{4695}, \frac{\mathrm{B}}{4703}, 707, \frac{\mathrm{G}}{401}$, and $\frac{\mathrm{G}}{558}$.

As previously mentioned (Ewing, 1924), the lice from Peruvian Indian mummies were found to be "slightly different" from those of the mummies from the southwestern part of the United States. Those from Peru are slightly suggestive of the corporis form in the segmentation of the antennae, there being a rather noticable distal enlargement of segments II, III, and IV. Also all the ventral setae of the Peruvian lice are more peglike than those of the New Mexico type, this being particularly true of the ventro-lateral pair of segment VI.

To this variety should be referred a lot of 4 males and 3 females and 1 nymph taken from an Indian woman at Coban, Guatemala, (Bishopp 10403) and a lot consisting of 1 female, 3 males, and 1 male nymph taken on the island of Trinidad, race of host unknown. These lice from Trinidad are slightly smaller, on the average, than those taken from the Indian mummies, but they agree with the mummy lice in essential characters. A lot of lice from a Greenland Eskimo and another from an Aleutian Eskimo, or probably more correctly an Aleutian mixed breed, do not belong to the variety americanus.

\section{PEDICULUS (PEDICULUS) HUMANUS hUMANUS Linnaeus.}

Plate 3 , fig. 8 ; text figs. $1 \mathrm{~A}, 2,3 \mathrm{~A}, 7$

1758 Pediculus humanus Linnaeus (part), Syst. Nat., ed. 10, p. 610.

1766 Pediculus humanus, variety $I$ Linnaeus, Syst. Nat., ed. 12, vol. 2, p. 1016.

1778 Pediculus humanus, variety capitis DE GeER, Mem. Hist. Ins., vol. 7, p. 67 , pl. 1 , fig. 6 .

1817 Pediculus cervialis LeACH, Zool. Misc., vol. 3, p. 66.

1818 Pediculus capitis Nitzsch, Germar's Mag., vol. 3, p. 305.

1842 Pediculus capitis Denny, Mon. Anop., p. 13, pl. 26, fig. 2.

1874 Pediculus capitis Gieber, Ins. Epizoa, p. 30, pl. 1, figs. 1-2.

1880 Pediculus capitis Piaget, Les Ped., p. 619, pl. 51, fig. 2.

1908 Pediculus capitis Dalla TorRe, Anoplura Gen. Ins., p. 8, pl. figs. $1 a$ and $1 b$.

1910 Pediculus capitis MJöвевg (part), Ark. f. Zool., vol. 6, no. 13, p. 168. 
1912 Pediculus capitis Fahrenholz, Jahresb. d. Niedersach. Zool. Ver., p. 2, figs. $1,3,7$, pl. 3 , figs. $3-4$.

1916 Pediculus capitis Ferris, Proc. Cal. Acad. Sci., ser. 4, vol. 6, p. 136. 1919 Pediculus humanus, race capitis Nuttall (part), Parasitology, vol. 11 , p. 334.

1920 Pediculus humanus, race capitis Nuttall (part), Parasitology, vol. 20, p. 152.

Female--Head with well-developed, poorly chitinized neck region; forehead about as broad as long; postocular tubercles well chitinized and with stiff spinelike setae. Antennae considerably shorter than the head; first segment about twice as broad as long; second segment about one and a half times as long as broad; third segment slightly longer than broad; fourth segment of equal length and breadth; fifth segment about one and a half times as long as broad. Macrochaetae of thorax not equal, the second pair being longer than the others; macrochaeta I about one-half as long as the width of coxa I; macrochaeta III situated less than the diameter of the thoracic spiracle (bulb of spiracle) behind the same. Posterior marginal setae of thorax about fourteen in number on each side; not far from the median line are two pairs of these setae, one pair above the other, which are larger than the others. Thoracic spiracles the largest of any variety of $P$. humanus, being $0.134 \mathrm{~mm}$. in diameter (across the bulb). Abdomen long and rather slender; setae, almost without exception, spinelike or peglike and most of them are not arranged in transverse rows; ventral side of sixth abdominal segment with 11 or 12 setae in transverse row, ventro-lateral pair but little if any larger than the setae in row, discal setae, about 24 in number, are almost as large as those in the row. Pleural plates (fig. 1, A) usually well pigmented; plate I irregularly squarish; plate II slightly larger than I and more distinctly squarish; plate III larger than II, IV larger than III, V larger than IV, and all of these more or less squarish; plate VI broader than long, rounded and with spiracle in the middle; plate VII very small, as broad as long. Legs rather short; femur $\mathrm{I}$, one and a half times as long as broad; tibia I about twice as long as broad. Tubercle on femur III rather conspicuous and well chitinized.

Length of an average-sized, unengorged female, $2.75 \mathrm{~mm}$; width, $0.90 \mathrm{~mm}$.

Male.-Leg I enlarged as usual; first tarsal segment about as broad as long, second tarsal segment about one and a half times as long as broad. Chaetotaxy of thumb of tibia I (fig. 7) as follows: Chief, or terminal, spine extending beyond margin of thumb by less than half its length; anterior accessory spine situated almost on the inside of thumb, spinelike and somewhat longer than terminal 
thumb; (in this variety of $P$. humanus one of the setae on the anterior side of the thumb is situated nearer the tip of the thumb than the usual accessory spine, and this seta is in this instance decidedly spinelike, hence apparently there are two anterior accessory spines); outer posterior accessory spine very long, situated nearer the outer margin of the thumb than the chief spine and extending beyond the margin of thumb by over one-half its length; inner posterior accessory spine the stoutest of all the accessory spines and about as long as the chief spine. Femur III without indication of posterior tubercle. Pleural plates similar to those of female except for plate I which is smaller, more irregular in shape and less squarish.

Length of medium-sized individual, $2.30 \mathrm{~mm}$.; width, $0.70 \mathrm{~mm}$. Type host and type locality.-By process of elimination the Caucasian race of mankind has become type host. No type locality.

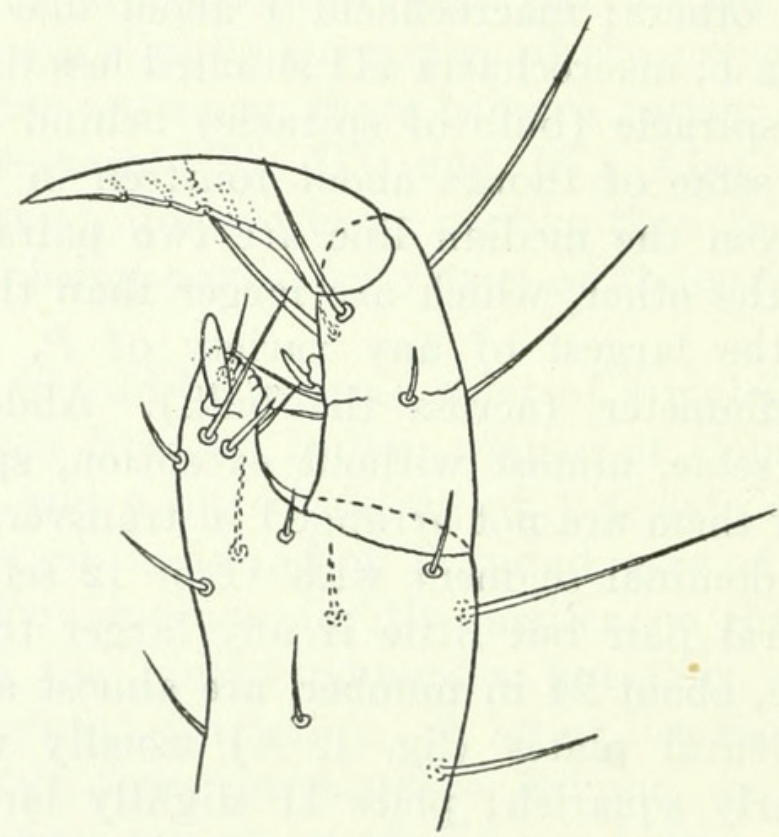

Fig. 7.-Ventral, or posterion, view of end of Left anterior leg of Male of pediculus (pediculus) humanus Linnaeus, taken in Germany

This description is based upon a lot of 3 females and 3 males collected at Eberswalde, Germany, by Doctor Krausse. By comparing these specimens with the descriptions of the early entomologists of Europe for the type of head louse found on white man the writer is convinced that they really represent the $P$. humanus humanus of Linnaeus. The variety stands out conspicuously among the pure varieties of the head lice of mankind studied by the writer in several respects. First, it is more slender, with somewhat shorter antennae, the thoracic spiracles are decidedly larger in proportion to the size of the body, the body setae are more numerous and nearly all of them are peglike or spinelike and less than half of them are in transverse rows, the chaetotaxy of the thorax is distinctive, and a few other characters of minor importance are noted. 
Although the writer has examined many lots of Pediculus from man he has seen no other lot that he would refer unqualifiedly to this variety, although some taken from an Eskimo in Greenland are near it and not at all of the type of $P$. humanus americanus or $P$. humanus angustus.

Head lice commonly found in America are of various types. Most of them appear to be either hybrids between the American Indian head louse, and the Caucasian head louse; or between the Caucasian head louse, and the Caucasian body louse, or the louse of the American negro; our American negro apparently has no distinctive head or body louse.

\section{GEOGRAPHICAL AND HOST DISTRIBUTION OF THE GENUS PEDICU- LUS IN THE NEW WORLD}

The problem of the host distribution of Pediculus in America is the most interesting, in the writer's opinion, of that of any genus of any group of ectoparasites. In this genus are found species so closely allied in their structural characters that more than one authority has claimed that they belong to a single species, yet the hosts of these closely related species are so far separated that not only are they regarded as belonging to different families but to families that are held by mammalogists to have no immediate phylogenetic relationships.

As has been shown in previous pages of this paper, the Atelesinfesting species and those infesting man are in reality not so nearly related structurally as has been supposed, and in fact are amply distinct in regard to the shape of the typical pleural plates. Yet, granting these essential differences, the conviction still remains that by comparison with other Anoplura of primates all species of Pediculus are remarkably alike.

As previously stated, different theories may be advanced to explain this unusual diversity of the two kinds of hosts. Kellogg (1913) believed that the close relationship shown by the Pediculi themselves indicated some sort of phylogenetic relationship of the hosts.

The writer's suggestions (Ewing, 1924) in regard to the significance of the host distribution of Pediculus in America, are two: First, it may be that here we have a case of a crossing over of the parasites from their original and favored hosts to another distantly related host group. In other words, it would appear that the spider monkeys obtained their pediculids from man, when the latter reached tropical America in his dispersion from the Old World. That such a crossing over from one host group to another with no near phylogenetic relationhip has taken place appears very probable in the case of the biting lice of the family Gyropidae (Ewing, 1924). 
That these Gyropid lice have as their favored hosts certain groups of rodents appears almost certain, since it is on rodents that nearly all the species are found, and it is on certain rodents that those members of the family with the most generalized structures occur. Yet several species of Gyropidae occur in nature on American ungulates and upon these ungulates are unusually prolific.

In regard to the theory that Ateles species have acquired their Pediculids from man, it is important to note that the pelage of the monkey-hosts is very similar to that of the head of man in coarseness and abundance, also that the blood of Ateles is physiologically more nearly like that of man than the blood of most monkeys.

On the skins of their hosts lice find themselves in a portable habitat, and, in the case of mammal-infesting lice, one that differs from that of free-living species in that its temperature is uniform or nearly so. Except for these two elements, portability and uniformity of temperature, the pelage environment of a louse is to be compared exactly to the grass environment of a grasshopper or the forest environment of a sloth. Having two similar environments in nature for a certain free-living species, we observe that the breaking down of a natural barrier between them causes the inhabitants of the one to spread and occupy the other. Having similar environments for Pediculus in the head of man and in the fur coat of Ateles it is conceivable that the breaking down of the natural barriers by the invasion by man of the territory of the monkeys and by his intimate association with them, might cause some of his lice to spread to a simian environment.

The second explanation advanced by the writer (Ewing, 1924) is that in Pediculus we have one of those generalized types which is to an unusual degree free from the influences of its environment. If this is true we would expect it to be a very old type and one which is now found on widely diversified host groups. Some of the Mallophagan genera, Philopterus for example, are found on a great many bird groups, both land and acquatic. If this be the true explanation we must expect Pedicutus to be eventually recorded from several diverse groups of primates. In this connection it should be noted that Fahrenholz (1913 and 1917) reports Pediculus from various species of gibbons (Hylobates) of the Old World.

If the phylogeny of the Ateles-infesting Pediculids has followed that of their hosts it is observed from our knowledge of them that the lice have been in America for a long geological period. According to Elliot (1913), the genus Ateles has a very great area of distribution (fig. 8) extending from south central Brazil to as far north as the state of Vera Cruz, Mexico, and on the continent of South America from the Pacific slope of Ecuador to the Atlantic coast of 
Brazil. In this vast area, in which the monkeys are found only in the forests, the genus is broken up into geographical species, as for example; Ateles pan is found from the state of Vera Cruz, Mexico, south into Guatemala; Ateles fusciceps is found in Trans-Andean Ecuador, and Ateles hybridus is limited to the valley of the Magdalena, Colombia. Species differentiation in this group appears to have followed dispersion, and this dispersion shows a spread over an immense area several thousands of miles in extent.

If the first suggestion, the "cross-over theory," is rejected, we then find that the solution of the distribution problem of Pediculus and the problem of the origin of the genus in the Americas become de-

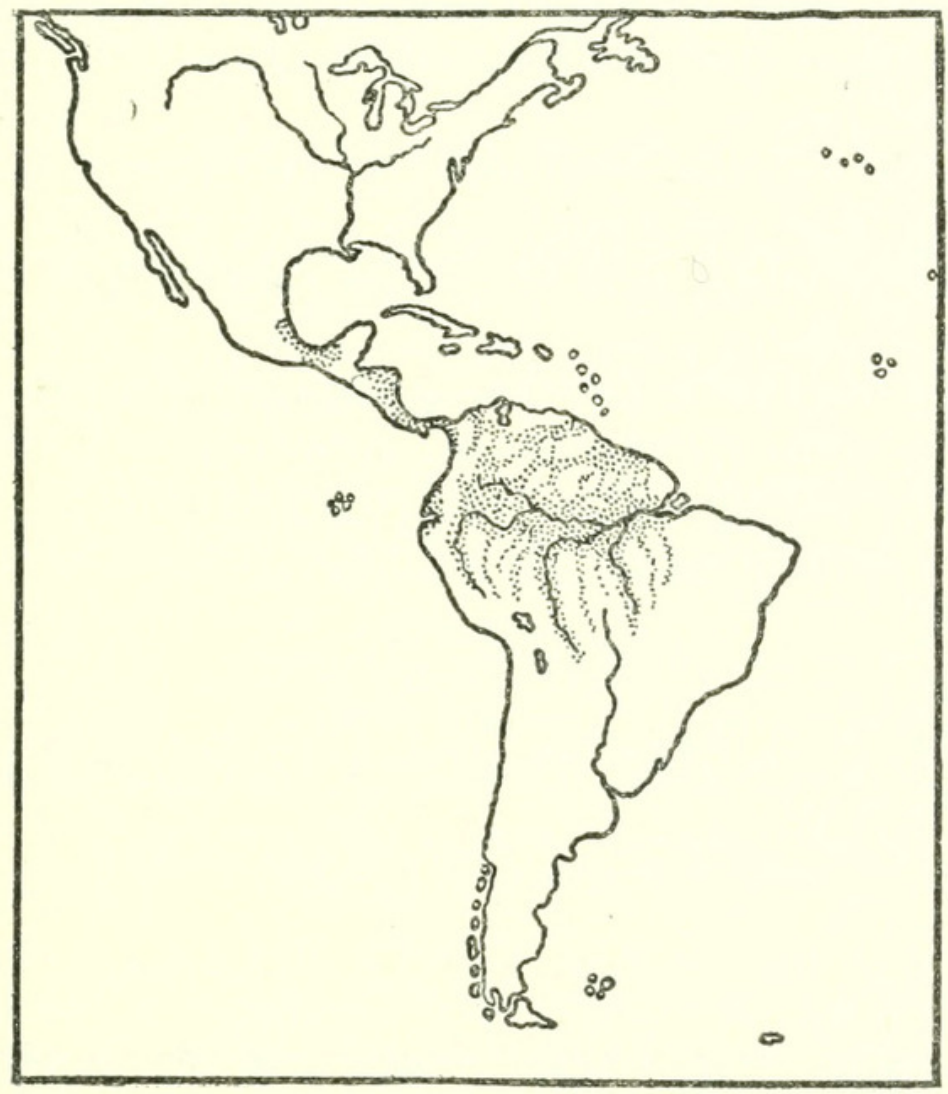

Fig. 8.-Map Showing the distribution of Spider MONKEys (ateles), based Chiefly oN RECORDS GIVEN BY ElliotT

pendent upon that of the distribution and origin in this continent of the hosts. The problem then hinges upon the work of the mammalogist more than on that of the entomologist.

\section{SUMMARY}

1. In America two distinct groups of Pediculus exist, one of them confined to man and one to monkeys.

2. The forms infesting man are apparently largely hybrid races of head lice, the pure strains of which were originally found on the white, black, red, and yellow races of man living in their original geographic range. 
3. The pure races of these head lice should be regarded as distinct varieties, for they differ in definite morphological characters.

4. Most of the characters used by the earlier entomologists for separating these varieties of man-infesting pediculi are not reliable since they are based either upon characters of hybrids, or characters that come under the category of individual variation, or those due to faulty technique.

5. No evidence was procured during this investigation indicating that the different primary races of mankind each harbored a different variety of clothes louse, as well as a different variety of head louse. The opinion still prevails that in certain races of man a distinct variety of clothes louse developed from the head-louse type for that race; while in other races no clothes-louse type distinctive from the head louse developed.

6. The monkey-infecting pediculids of America, so far as known, fall into distinct species according to the hosts they infest, thus indicating, to a certain degree at least, a parallel host and parasite phylogeny.

7. If these monkey hosts (Ateles, species) procured their lice from man it was not from recent man but from human hosts that lived tens of thousands of years ago-long enough to allow a species differentiation to develop among the monkey hosts.

\section{Bacot, A.}

\section{REFERENCES.}

1917. A Contribution to the Bionomies of Pediculus humanus (vestimenti) and Pediculus capitis. Parasitology, vol. 9, pp. 228-258, 4 figs.

Dalla Torre, von K. W.

1908. Genera Insectorum, Anoplura, 22 p., 1 pl.

De Geer, C.

1778. Mem. Hist. Ins., vol. 7, pt. 1, pp. 62-69, pl. 1, figs. 6-10.

Denny, H.

1842. Monographia Anoplurorum Britanniae, 262 pp., 26 pls.

Elliot, D. G.

1913. A Review of the Primaries. Amer. Mus. Nat. Hist., Mon. Ser., vol. 2, (part on Ateles) pp. 21-48, pls. 2-3.

Enderlein, G.

1904. Läuse-Studien. Zool. Anz., vol. 28, p. 121-147, 15 figs.

Ewing, H. E.

1924. On the Taxonomy, Biology and Distribution of the Biting Lice of the Family Gyropidae. Proc. U. S. Nat. Mus., vol. 63, art. 20, pp. 1-42, 18 figs., 1 pl.

1924. Lice from Muman Mummies. Science, vol. 9, no. 1556, pp. 389-390. Fahren holz, Von H.

1912. Beiträge zur Kenntnis der Anopluren. Jahresb. d. Niedersach. Zool. Ver., ser. 2, pp. 1-60, figs. 1-23, pls. 1-3.

1913. Ectoparasiten und Abstammungslehre. Zool, Anz., vol. 41, pp. 371-374.

1915. Läuse verschiedener Menschenrassen. Zeitsch. f. Morph. u. Anthrop., vol. 17, pp. 591-602, figs. 1-5 b.

1917. Diagnosen neuer Anopluren, III. Zool. Anz., vol. 48, pp. 87-93. 
Ferris, G. F.

1916. A Catalogue and Host List of the Anoplura. Proc. Cal. Acad. Sci., ser. 4, vol. 6, no. 6, pp. 129-213.

Giebel, C. G.

1874. Insecta Epizoa, pp. 27-32, pl. 1, figs. 1, 2, 5.

LEACH, W. E.

1817. Zoological Miscellany, vol. 3, pp. 66-67

Linnaeus, C.

1758. Systema Naturae, ed. 10, vol. 1, pp. 610-614.

1766. Systema Naturae, ed. 12, vol. 2, p. 1016.

MJöвеrg, E.

1910. Studien über Mallophagen und Anopluren. Ark. f. Zool., vol. 6, no. 13, pp. 1-296, 5 pls., 156. figs.

NEUManN, L. G.

1911. Notes sur les Pédiculidés.-II. Arch. Par., vol. 14, pp. 401-414, figs. $1-8$.

Nitzsch, C. L.

1818. Germar's Mag. Ent., vol. 3, pp. 304-305.

Nuttall, G. H. F.

1919. The Systematic Position, Synonymy and Iconography of PedicuTus humanus and Phthirus pubis. Parasitology, vol. 11, pp. 329-346.

1920. On Fahrenholz's Purported New Species, Subspecies and Varieties of Pediculus. Parasitology, vol. 12, pp. 136-153.

OLFers, I. F. M.

1916. De vegetativis et animatis corporibus in corporibus anincatis reperiundis commentarius. Pars. I, Berlin.

Plaget, E.

1880. Les Pédiculines. 714 pp., 56 pls.

1855. Les Pédiculines; Supplement. 162 pp., 17 pl.

\section{EXPLANATION OF PLATES.}

All photographs were made by J. G. Pratt, and all are of the same magnification, X 20.

\section{Plate 1.}

F1g. 1. Pediculus (Parapediculus) consobrinus Piaget; male, from above.

2. Pediculus (Parapediculus) consobrinus Piaget; female, from above.

3. Pediculus (Parapediculus) chapini, new species; male, from below.

4. Pediculus (Parapediculus) chapini, new species; female, from above.

\section{Plate 2.}

Fig. 5. Pediculus (Parapediculus) lobatus Fahrenholz; incompletely formed female inside of last nymphal skin; from above.

6. Pediculus (Pediculus) humanus nigritarum Fabricius; male, taken from negro boy in Africa; ventral view.

7. Pediculus (Pediculus) humanus nigritarum Fabricius; female, taken from negro boy in Africa; ventral view.

Plate 3.

Fig. 8. Pediculus (Pediculus) humanus humanus Linnaes; female, taken in Germany; dorsal view.

9. Pediculus (Pediculus) humanus americanus, new variety; female, taken from the scalp of a prehistoric American Indian mummy collected at Canyon del Muerto, New Mexico; ventral view. 
FIg. 10. Pediculus (Pediculus) humanus americanus, new variety; female, taken from the scalp of a prehistoric American Indian mummy, collected at Surco, Peru; ventral view.

11. Pediculus (Pediculus) humanus americanus, new variety; male, taken from the scalp of a prehistoric American Indian mummy, collected at Canyon del Muerto, New Mexico; ventral view.

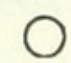




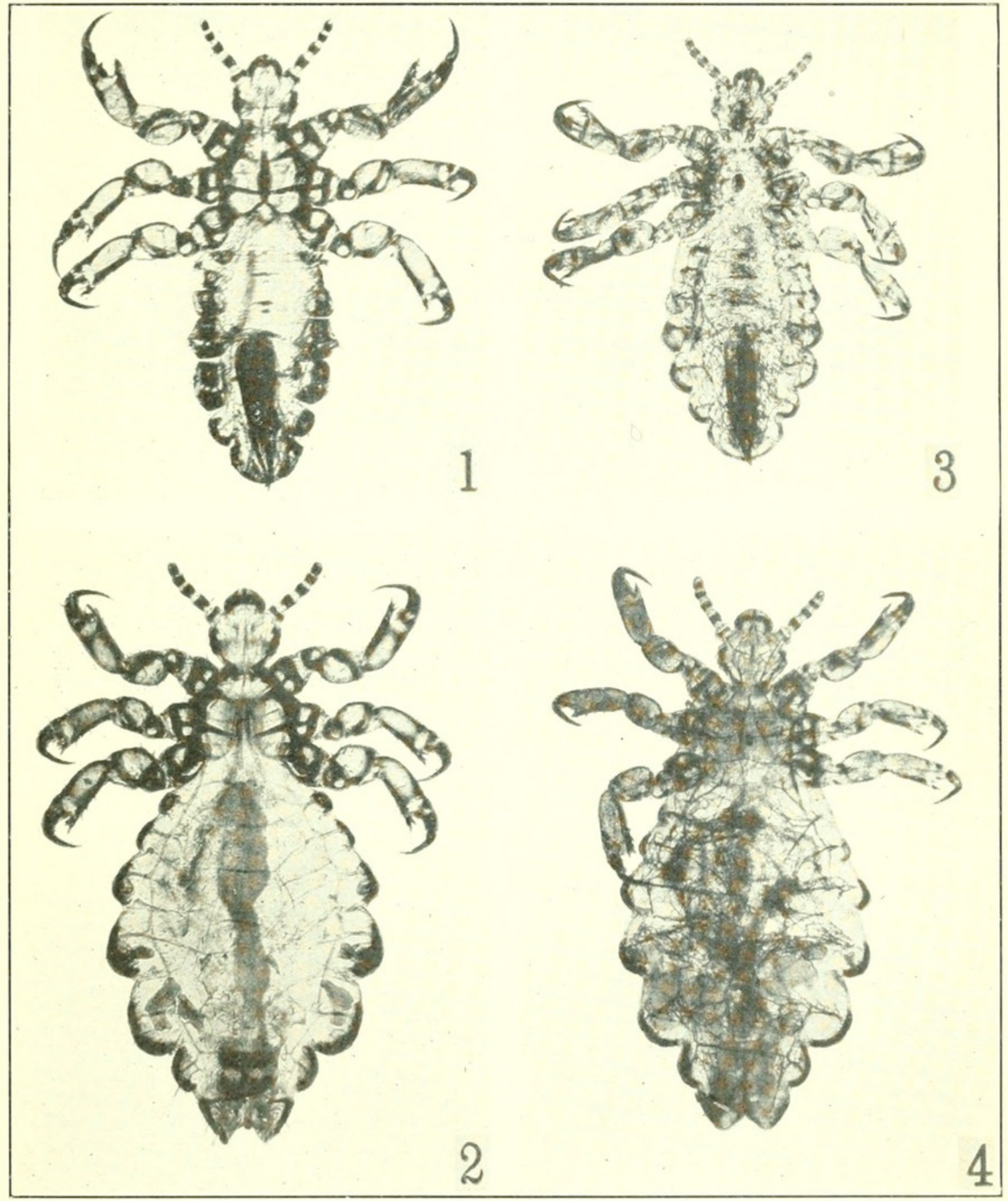

PEDICULI FROM MONKEYS

FOR EXPLANATION OF PLATE SEE PAGE 29 


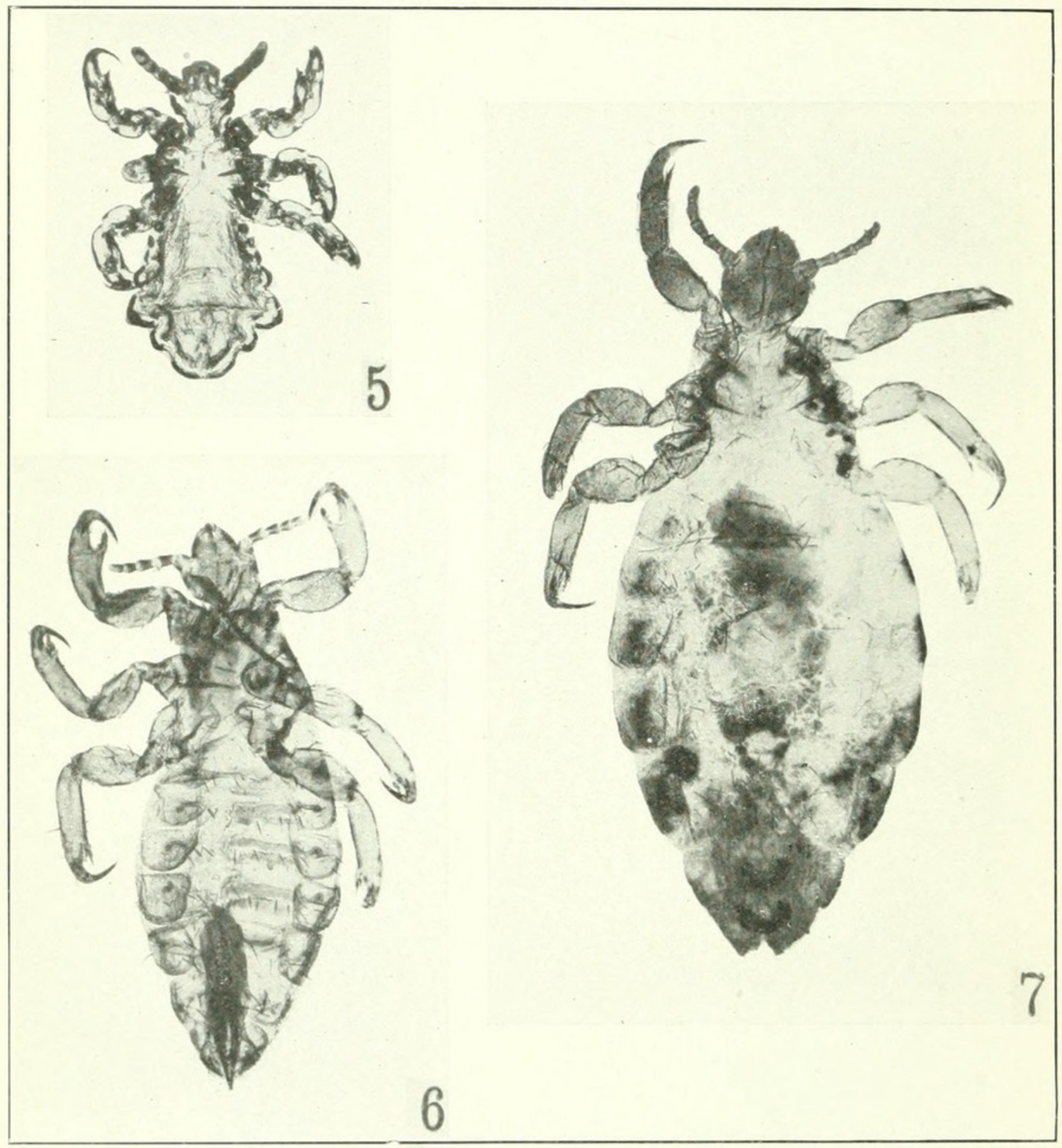

Pediculi from a Monkey and from Negroes

For EXPLANATION OF PLATE SEE PAGE 29 


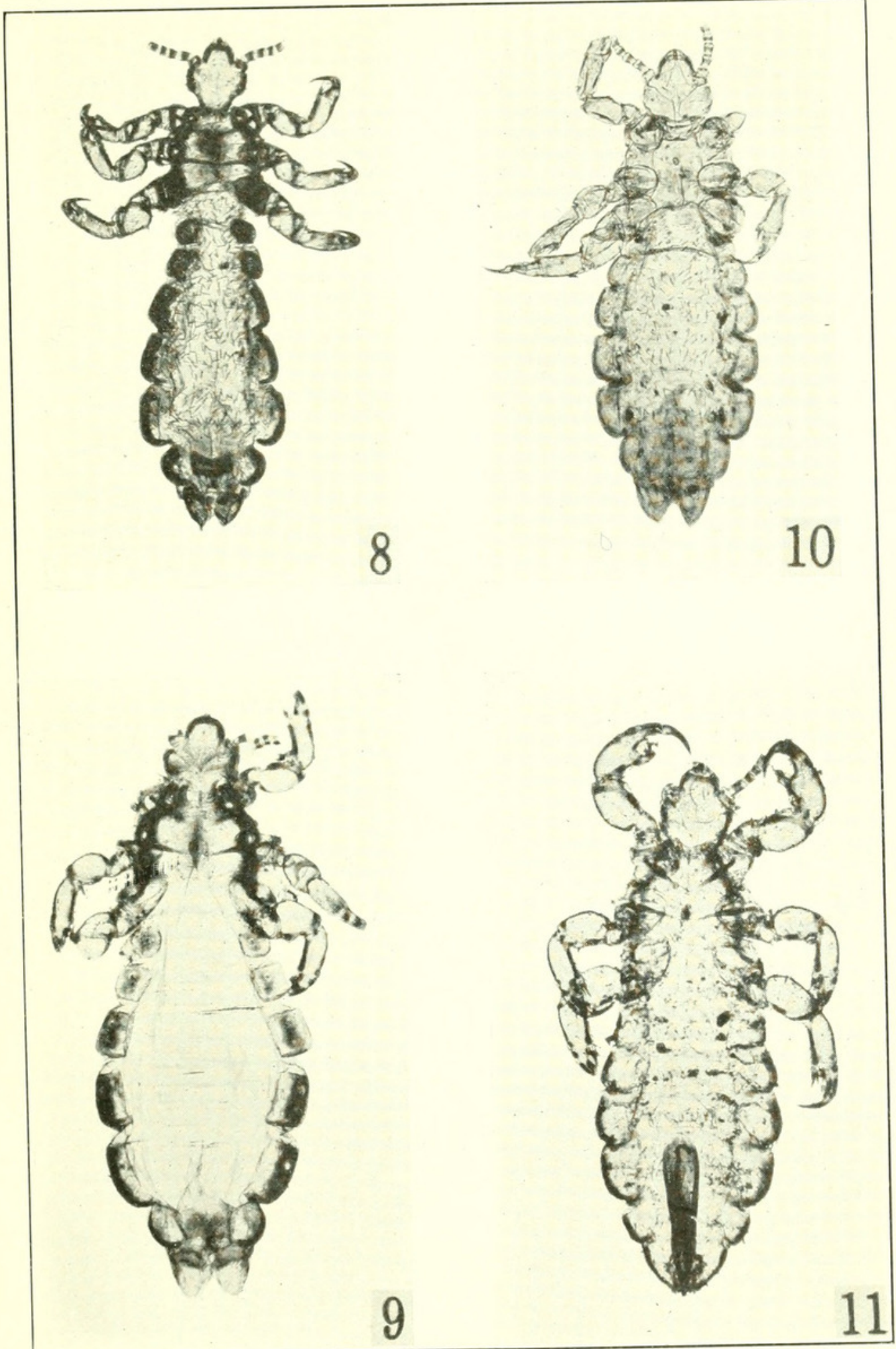

PEDICULI FROM MAN

For EXPLANATION OF PLATE SEE PAGES 29 AND 30 




\section{$2 \mathrm{BHL}$ Biodiversity Heritage Library}

Ewing, H. E. 1926. "Revision of the American leafhoppers of the Jassid genus Typhlocyba." Proceedings of the United States National Museum 68, 1-47. https://doi.org/10.5479/si.00963801.68-2620.1.

View This Item Online: $\underline{\text { https://www.biodiversitylibrary.org/item/32569 }}$

DOI: https://doi.org/10.5479/si.00963801.68-2620.1

Permalink: https://www.biodiversitylibrary.org/partpdf/5759

\section{Holding Institution}

Smithsonian Libraries

\section{Sponsored by}

Smithsonian

\section{Copyright \& Reuse}

Copyright Status: NOT_IN_COPYRIGHT

Rights: https://www.biodiversitylibrary.org/permissions/

This document was created from content at the Biodiversity Heritage Library, the world's largest open access digital library for biodiversity literature and archives. Visit BHL at https://www.biodiversitylibrary.org. 